\title{
Diagnosis and management of prolactinomas: current challenges
}

\author{
Stephan Petersenn ${ }^{1} \cdot$ Andrea Giustina $^{2}$
}

Published online: 3 January 2020

(c) Springer Science+Business Media, LLC, part of Springer Nature 2020

Prolactinoma is the most frequent pituitary adenoma type, accounting for $40-66 \%$ in epidemiological studies [1]. The estimated prevalence in various populations ranges from 25/100,000 to 63/100,000 [2], with standardized incidence rates between 2.1 and 5.4 cases/100,000/year [1]. Considering the frequency of prolactinomas and their potential clinical significance, it is pertinent that a special issue of PITUITARY is devoted to current challenges in their management.

Results from a large autopsy study suggest a high number of unrecognized prolactinomas [3]. Pituitary adenomas were detected in $10.4 \%$ of autopsy cases, with prolactinomas representing $40 \%$ and being far more frequent than null cell adenomas as second frequent type with $23 \%$. To better understand, why a notable number of prolactinomas remain undiagnosed or clinically insignificant, whereas others present with relevant clinical symptoms or even develop an aggressive behavior, a precise characterization of cellular differences is important. In her report on 'Pathology of prolactinomas-any predictive value?' Lopes discusses potential prognostic markers which support development of a clinical classification [4]. Furthermore, to aid early detection and correct diagnosis of unrecognized prolactinomas, Petersenn in his article 'Biochemical diagnosis of prolactinomassome caveats' reviews potential pitfalls when measuring prolactin [5]. If sufficient clinical and biochemical evidence supports the diagnosis of a prolactinoma, MRI scan will be necessary to confirm the presence of an underlying pituitary adenoma. In their review on 'Magnetic resonance imaging in the management of prolactinomas; a review of the evidence' Varlamov et al. present an update on MRI techniques and the problem of gadolinium deposits, suggesting clinical scenarios necessitating imaging procedures [6]. This hopefully will

Stephan Petersenn

stephan.petersenn@endoc-med.de

1 ENDOC Center for Endocrine Tumors, Erik-Blumenfeld-Platz 27a, 22587 Hamburg, Germany

2 Endocrinology Unit, Ospedale San Raffaele and Università Vita-Salute San Raffaele, Milan, Italy result in well thought through and less frequent requests for MRI scans during follow-up of patients with prolactinoma.

In contrast to all other pituitary tumor types, the vast majority of prolactinomas responds excellently to medical treatment. Especially the long-acting dopamine agonists have demonstrated high efficacy rates of more than $80 \%$ stable normoprolactinemia with acceptable side effects [7]. Furthermore, reduction in tumor size is demonstrated in at least $60 \%$ of patients treated by dopamine agonists [8]. Still, resistance to medical treatment does occur. In her article 'Dopamine agonist resistant prolactinomas - any alternative medical treatment?', Souteiro and Karavitaki discuss limitations of other medical therapies in those patients [9].

Long-term studies in patients with Parkinson's disease treated with high dopamine agonist doses have cast a shadow on the use of dopamine agonists [10]. A recent meta-analysis confirmed a significant increase in tricuspid regurgitation in patients treated with cabergoline for hyperprolactinemia, although with unknown clinical significance [11]. Another meta-analysis summarized psychological effects of dopamine agonists, including impulse control disorders, depression, manic episodes, and psychosis requiring increased awareness [12]. Repeated trial of therapy discontinuation may help reduce life-long risk of dopamine agonist side effects, as described by Souteiro et al. in their review 'Dopamine agonists in prolactinomas-when to withdraw?' [13]. Furthermore, surgery may regain momentum as first line therapy in selected patients, as described by Honegger et al. in their review 'Surgery for prolactinomas-a better choice?' [14].

Standard treatment in prolactinomas needs to be adapted in certain clinical conditions presenting specific challenges. Macroprolactinomas in men tend to demonstrate a more aggressive behavior, as reviewed by Duskin-Bitan and Shimon in their article 'Prolactinomas in Males-any Differences?' [15]. Treatment goals may change in menopause, with physiological decline in sex hormones. Potential morbidity by prolactin excess independent of its effects on breast and gonads is critically reviewed by Greenman in her article 'Prolactinomas and Menopause: any changes 
in management?' [16]. Pregnancy in women with prolactinomas poses specific challenges, as the fetus is inevitably exposed to dopamine agonists at least for the time until gestation is confirmed. A recent multi-center study from Brazil suggests increased miscarriage rate in patients maintained on cabergoline during pregnancy [17]. Glezer and Bronstein in their review 'Prolactinomas in pregnancy-considerations before conception and during pregnancy' propose an algorithm for management of women with prolactinoma and who wish to become pregnant [18]. Rarely, prolactinomas may exhibit aggressive behavior, as defined by an unusually rapid tumor growth or clinically relevant tumor growth despite optimal standard therapy [19]. Lasolle et al. in their article 'Aggressive prolactinomas-how to manage?' summarize current therapeutic options in those patients [20].

We are very grateful to our colleagues who have reviewed the current evidence for the management of those challenges. We hope that this special issue improves the care of patients with prolactinoma and stimulate further research and studies in those areas with need for improvement. Our sincere thanks go to Shlomo Melmed, Pituitary editor-inchief, all contributing authors, and Springer editorial staff to facilitate this special issue.

Funding No funding.

\section{Compliance with ethical standards}

Conflict of interest Authors SP and AG declare that they have no conflict of interest.

Ethical approval This article does not contain any studies with human participants performed by any of the authors.

\section{References}

1. Vroonen L, Daly AF, Beckers A (2019) Epidemiology and management challenges in prolactinomas. Neuroendocrinology 109:20-27

2. Chanson P, Maiter D (2019) The epidemiology, diagnosis and treatment of prolactinomas: the old and the new. Best Pract Res Clin Endocrinol Metab 33(2):101290

3. Buurman H, Saeger W (2006) Subclinical adenomas in postmortem pituitaries: classification and correlations to clinical data. Eur J Endocrinol 154:753-758

4. Lopes MBS (2019) Pathology of prolactinomas: any predictive value. Pituitary. https://doi.org/10.1007/s11102-019-00997-1

5. Petersenn S (2019) Biochemical diagnosis in prolactinomas: some caveats. Pituitary. https://doi.org/10.1007/s11102-019-01024-z

6. Varlamov EV, Hinojosa-Amaya JM, Fleseriu M (2019) Magnetic resonance imaging in the management of prolactinomas: a review of the evidence. Pituitary. https://doi.org/10.1007/s11102-01901001-6

7. Webster J, Piscitelli G, Polli A., Ferrari CI, Ismail I, Scanlon MF (1994) A comparison of cabergoline and bromocriptine in the treatment of hyperprolactinemic amenorrhea. Cabergoline Comparative Study Group. N Engl J Med 331, 904-909

8. Melmed S, Casanueva FF, Hoffman AR, Kleinberg DL, Montori VM, Schlechte JA, Wass JA, Endocrine S (2011) Diagnosis and treatment of hyperprolactinemia: an Endocrine Society clinical practice guideline. J Clin Endocrinol Metab 96:273-288

9. Souteiro P, Karavitaki N (2019) Dopamine agonist resistant prolactinomas: any alternative medical treatment. Pituitary. https:// doi.org/10.1007/s11102-019-00987-3

10. Biller BM, Colao A, Petersenn S, Bonert VS, Boscaro M (2010) Prolactinomas, Cushing's disease and acromegaly: debating the role of medical therapy for secretory pituitary adenomas. BMC Endocr Disord 10:10

11. Stiles CE, Tetteh-Wayoe ET, Bestwick J, Steeds RP, Drake WM (2018) A meta-analysis of the prevalence of cardiac valvulopathy in hyperprolactinemic patients treated with Cabergoline. J Clin Endocrinol Metab. https://doi.org/10.1210/jc.2018-01071

12. Ioachimescu AG, Fleseriu M, Hoffman AR, Vaughan TB III, Katznelson L (2019) Psychological effects of dopamine agonist treatment in patients with hyperprolactinemia and prolactinsecreting adenomas. Eur J Endocrinol 180:31-40

13. Souteiro P, Belo S, Carvalho D (2019) Dopamine agonists in prolactinomas: when to withdraw. Pituitary. https://doi.org/10.1007/ s11102-019-00989-1

14. Honegger J, Nasi-Kordhishti I, Aboutaha N, Giese S (2019) Surgery for prolactinomas: a better choice? Pituitary. https://doi. org/10.1007/s11102-019-01016-Z

15. Duskin-Bitan H, Shimon I (2019) Prolactinomas in males: any differences. Pituitary. https://doi.org/10.1007/s11102-019-01009 $-\mathrm{y}$

16. Greenman Y (2019) Prolactinomas and menopause: any changes in management. Pituitary. https://doi.org/10.1007/s11102-01900998-0

17. Sant' Anna BG, Musolino NRC, Gadelha MR, Marques C, Castro M, Elias PCL, Vilar L, Lyra R, Martins MRA, Quidute ARP, Abucham J, Nazato D, Garmes HM, Fontana MLC, Boguszewski CL, Bueno CB, Czepielewski MA, Portes ES, Nunes-Nogueira VS, Ribeiro-Oliveira A, Francisco RPV, Bronstein MD, Glezer A (2019) A Brazilian multicentre study evaluating pregnancies induced by cabergoline in patients harboring prolactinomas. Pituitary. https://doi.org/10.1007/s11102-019-01008-z

18. Glezer A, Bronstein MD (2019) Prolactinomas in pregnancy: considerations before conception and during pregnancy. Pituitary. https://doi.org/10.1007/s11102-019-01010-5

19. Raverot G, Burman P, McCormack A, Heaney A, Petersenn S, Popovic V, Trouillas J, Dekkers OM (2018) European Society of Endocrinology Clinical Practice Guidelines for the management of aggressive pituitary tumours and carcinomas. Eur J Endocrinol 178:G1-G24

20. Lasolle H, Ilie MD, Raverot G (2019) Aggressive prolactinomas: how to manage. Pituitary. https://doi.org/10.1007/s11102-01901000-7

Publisher's Note Springer Nature remains neutral with regard to jurisdictional claims in published maps and institutional affiliations. 